\title{
Intravitreal Bevacizumab in Diabetic Macular Edema at Dr. Cipto Mangunkusumo Hospital Jakarta in 2017
}

\author{
Masniah $^{1}$, Ari Djatikusumo², Elvioza², Gitalisa Andayani Adriono², Anggun Rama Yudantha², Mario Marbungaran \\ Hutapea $^{2}$, Andi Arus Victor ${ }^{2}$ \\ ${ }^{1}$ Brigjen Haji Hasan Basry Kandangan Hospital, Hulu Sungai Selatan \\ ${ }^{2}$ Department of Ophthalmology, Faculty of Medicine Universitas Indonesia
}

\section{ABSTRACT}

Introduction: Diabetic Macular Edema (DME) is a manifestation of diabetic retinopathy and is the most common cause of vision loss in diabetics. The incidence of DME has a tendency to increase, concomitant with the prevalence of diabetes globally by more than 50\% from 2000 to 2030. This study aims to evaluate the proportion of central macular thickness (CMT) improvement and visual acuity in DME patients treated with intravitreal bevacizumab (IVB) injection.

\begin{abstract}
Methods: This study is a retrospective descriptive study. The study was conducted in the Department of Ophthalmology, Dr. Cipto Mangunkusumo Hospital, Jakarta. Data were obtained from the medical records of all diabetic retinopathy patients with macular edema who were treated with IVB at Dr. Cipto Mangunkusumo Hospital in January - December 2017.

Results: Of the 44 subjects, improvement in best corrected visual acuity (BCVA) occurred in 24 (54.54\%) subjects at the first-month evaluation and 19 (43.18\%) subjects at the third-month evaluation. CMT decreased in $37(84.41 \%)$ subjects at the first-month evaluation and 35 (81.81\%) subjects at the third-month evaluation.

Conclusion: There are visual acuity improvement and central macular thickness reduction at 3 months after IVB injection. These results strengthen IVB injection to be an alternative to adjuvant therapy in DME.

\footnotetext{
Keywords: Diabetic Macular Edema, Intravitreal Bevacizumab Injection, Anti-VEGF Intravitreal Injection

Cite This Article: VICTOR, Andi Arus et al. Intravitreal Bevacizumab In Diabetic Macular Edema At RSUP Cipto Mangunkusumo in 2017. International Journal of Retina, [S.I.], v. 2, n. 2, sep. 2019. ISSN 2614-8536. Available at: https://www.ijretina.com/index.php/ijretina/article/view/70 https://doi.org/10.35479/ijretina.2019.vol002.iss002.70
}

*Correspondence to:

Andi Arus Victor,

Department of Ophthalmology Faculty of Medicine, Universitas Indonesia

arvimadao@yahoo.com

\section{INTRODUCTION}

Diabetic Macular Edema (DME) is the most common cause of vision loss in diabetic retinopathy. An increase in the prevalence of diabetes in Asia has a different unique pattern from other countries in the world. The increase in the number of diabetic retinopathy associated with type 2 diabetes mellitus (DM) also occurred in Asia over the past two decades. ${ }^{1}$

DME is retinal thickening or the presence of hard exudates within 1-disc diameters of the center of the macula in diabetic retinopathy. ${ }^{2}$,
3 DME causes the greatest decrease in central vision in patients with type 2 DM. 4,5 The incidence of DME has a tendency to increase, concomitant with the prevalence of diabetes globally by more than $50 \%$ from 2000 to 2030 , estimated to reach up to 300 million cases of diabetes in $2025 .{ }^{6}$ The Early Treatment Diabetic Retinopathy Study (ETDRS ) shows that $30 \%$ of patients with diabetes with clinically significant macular edema (CSME) have a risk of experiencing vision loss. ${ }^{7}$ 
The pathogenesis of DME is multifactorial and complex. Increased blood glucose levels and free radical formation/ oxidative stress, activation of protein kinase $C(P K C)$ and Advanced glycation end-product (AGEP) can change microstructure of blood vessels, then it causes ischemia in the retina. ${ }^{4,8}$ The ischemic hypoxic state causes an increase in vascular endothelial growth factor (VEGF) secretion, prostaglandins, and inflammatory cytokines. ${ }^{9}$

The development of DME is related to several important systemic factors in DM such as blood pressure, hyperglycemia levels, and lipid profiles. The duration of DM is one of the main factors in the development of macular edema. Based on a study conducted by the UK Prospective Diabetes Study (UKPDS) on patients with type 2 DM, it was shown that in ten years, patients who have strict metabolic control can prevent and slow the progression of existing diabetic retinopathy abnormalities. HbA1C levels are used to see the glycemic index in diabetics in the last 3 months, with normal limits below $7 \%$. The condition of hypertension can worsen endothelial function that has been damaged in diabetes mellitus. The target of blood pressure in diabetic retinopathy patients is normotension to prevent worsening retinopathy and other microvascular complications. The role of lipid profiles in diabetic retinopathy has not been known until now. However, increased serum lipid levels are associated with the development of hard exudates in macular edema. ${ }^{10}$

Management of DME including control of blood glucose levels, blood pressure, and lipid levels. ${ }^{11}$ The ETDRS reports that focal laser photocoagulation is standard therapy in patients with CSME, 5 however this therapy still has limitations. Intravitreal anti-VEGF injection is the main therapy for current DME. ${ }^{12}$ The use of Intravitreal Bevacizumab (IVB) injection proved effective on DME. ${ }^{13}$ Diabetic Retinopathy Clinical Research (DRCR) network stated improved visual acuity in the third week after antiVEGF injection. ${ }^{14}$ The effectiveness of IVB injection on reducing central macular thickness (CMT) begins at week 3 , persists for week $6,{ }^{14}$ and improvement in visual acuity occurs until week $36 .{ }^{15}$

Management of DME is still a hot topic in the world of ophthalmology. Research on the use of intravitreal injection as an adjuvant remained the topic of discussion. Previous study of IVB injection has been overwhelming, but there were a variety of the results. Adjuvant IVB injection is expected to have a synergistic effect with laser photocoagulation in reducing macular thickness. Therefore, this study aims to evaluate the outcome of intravitreal bevacizumab.

\section{METHODS}

This research is a retrospective descriptive study. The research data is secondary data obtained from medical records of diabetic retinopathy patients with macular edema. The study was conducted at Dr. Cipto Mangunkusumo Hospital, Jakarta Jakarta in April September 2018. The subjects were all diabetic retinopathy patients with macular edema who were treated with IVB injection at Dr. Cipto Mangunkusumo Hospital, Jakarta.

The inclusion criteria were all patients with diabetic retinopathy with new macular edema who had never received laser therapy, intravitreal anti-VEGF, and corticosteroids. Informed consent were gained from all subjects. Exclusion criteria were: 1) patients with a history of intraocular surgery in the last 6 months; 2) patients with glaucoma history; 3) patients with significant media opacities (corneal, lens and vitreous opacities)

Operational definition DME is central macular edema caused by diabetes. Types of diabetic retinopathy are grouped into Mild NPDR: microaneurysms only; Moderate NPDR: more than microaneurysm, but less than severe NPDR; Severe NPDR: any of the following abnormalities of 4-2-1 rule and no signs of PDR. The 4-2-1 rule is $\geq 20$ intraretinal bleeding in the four quadrants, or venous beading in $\geq 2$ quadrants, or Intraretinal Microvascular Abnormalities (IRMA) in $\geq 1$ quadrant; Very Severe NPDR: two / more of the above abnormalities and no signs of PDR.

BCVA is visual acuity obtained with the best glasses correction and measured by the ETDRS chart at a distance of 6 meters. The BCVA unit is logMar on the ETDRS chart. The measurements were taken pre-injection, 1st month, and 3rd month after injection.

Absolute CMT is the average thickness in the area of 500 $\mu \mathrm{m}$ from the central macula obtained from OCT examination in $\mu \mathrm{m}$ units. The measurement is done preinjection, 1st month, and 3rd month after injection.

\section{RESULTS}

Characteristics of Research Subjects in this study, a sample of 44 eyes was obtained from patients with diabetic retinopathy. Based on the data on demographic characteristics in this study, female more than male $(56.81 \%$ compared to $43.18 \%)$. 
Table 1. Demographic Characteristics of Subjects

\begin{tabular}{ll}
\hline Characteristics & $\begin{array}{l}\text { Intravitreal } \\
\text { Injection (n= 44) }\end{array}$ \\
\hline Age [median] (year) & 58,82 \\
\hline Male (\%) & $19(43,18 \%)$ \\
\hline Female (\%) & $25(56,81 \%)$ \\
\hline Types of DM & \\
\hline Type 1 (\%) & $11(25,0 \%)$ \\
\hline Type 2 (\%) & $33(75,0 \%)$ \\
\hline Duration of DM (year) & 9,86 \\
\hline Blood Pressure & \\
\hline Hypertension (\%) & $23(52,27 \%)$ \\
\hline Non Hypertension (\%) & $21(47,72 \%)$ \\
\hline Types of Diabetic & \\
Retinopathy & \\
\hline Moderate NPDR (\%) & $8(18,10 \%)$ \\
\hline Severe NPDR (\%) & $23(52,2 \%)$ \\
\hline PDR (\%) & $13(28,10 \%)$ \\
\hline Lens & $31(70,45 \%)$ \\
\hline Phakic (\%) & $13(29,54 \%)$ \\
\hline Pseudophakic (\%) & \\
\hline
\end{tabular}

The demographic characteristics of the study subjects are summarized in table 1 . Mean age: 58,82 years old, the mean duration of DM: 9,86 years. The prevalence was higher in type 2 rather than type 1 DM. Severe NPDR was the highest prevalence in this study.

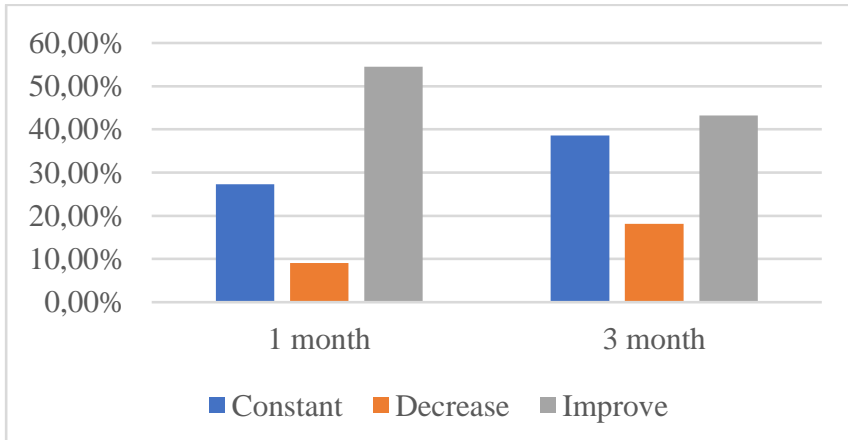

Figure 1. Best Corrected Visual Acuity 1 month and 3 months post IVB

In Figure 1, it can be seen that after IVB, the BCVA increases in the 1st month and 3rd month. Although in the 3rd month, the frequency of increased BCVA was decreased and the frequency of decreased BCVA was increased.

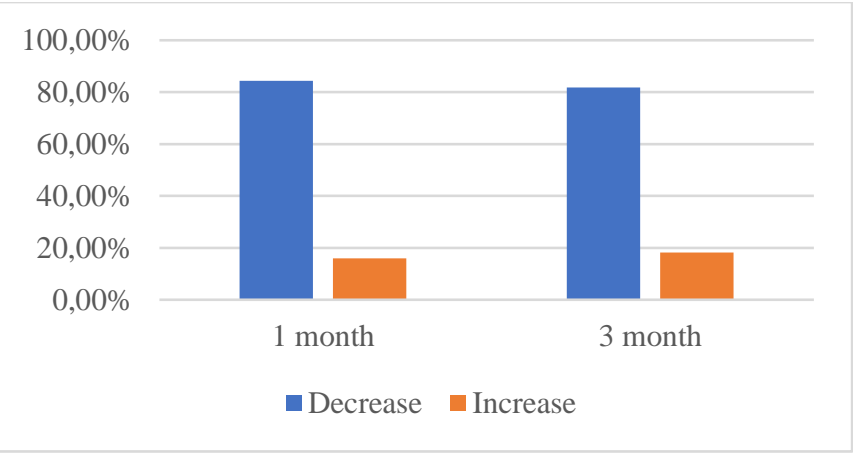

Figure 2. Central Macular Thickness 1 month and 3 month post IVB

Decreased in CMT occurred in most of the cases on month 1 and month 3.

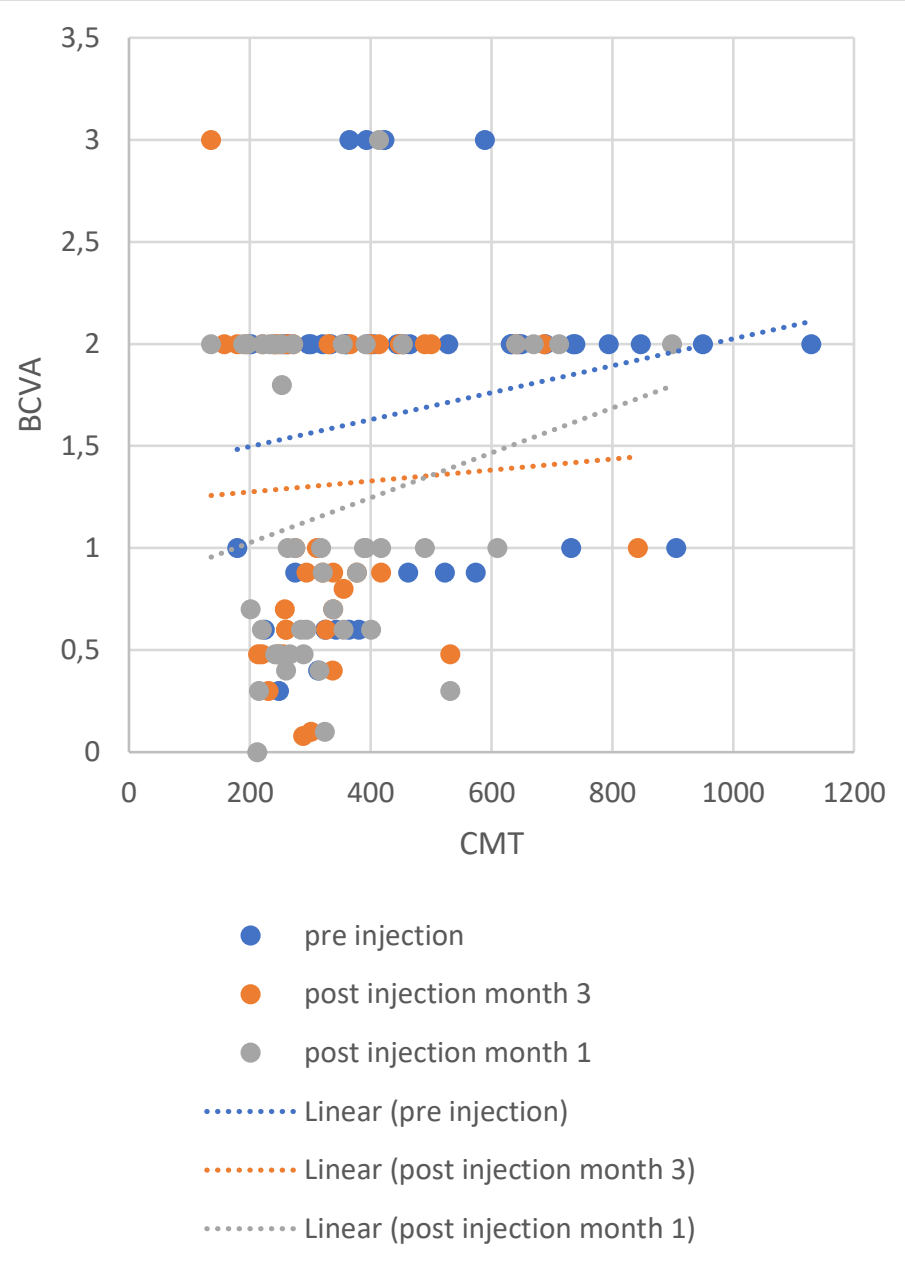

Figure 3. Scatter plot between CMT and BCVA pre and post IVB

The association between CMT and BCVA as seen from the scatter plot, improvement of BCVA occurred in reduced CMT. In this study, reduced CMT and improvement of BCVA were found after IVB injection. 
There were no ocular or systemic complications such as stroke, transient ischemic attack, or myocardial infarction after 3-month evaluation.

\section{DISCUSSION}

Bevacizumab is a human antibody that has specific ability to inhibit all subtypes of VEGF-A, a growth factor responsible in the pathophysiology of DME. Hypoxic state and hyperglycaemia in diabetic patients induce the production of VEGF leading to increased expression of ICAM-1. VEGF is responsible for the induction of angiogenesis and also the changes in tight junction of retinal vascular endothelial cells leading to disruption of blood-retinal barrier (BRB). The vascular leakage of fluid and plasma then accumulate in the intraretinal layer of the macula leading to the thickening of the retina and loss of the central vision. ${ }^{5,16}$

In this study, treatment of intravitreal bevacizumab showed an improvement in the BCVA and reduction of CMT reached the peak after 1 month after the procedure, the results continue to maintained or improved until 3 months of the evaluation. The same result also stated by Arevalo et $\mathrm{al}^{13}$ in a 6-month follow up study after primary intravitreal bevacizumab, they found the maximum benefit of IVB in changes of retinal thickening and visual acuity after the first month and maintained over 6 months. The study resulted in statistically significant improvement of visual acuity from the mean baseline BCVA 0.87 to final mean BCVA 0.6 and statistically significant reduction of CMT for mean baseline $387.0 \pm 182.8 \mu \mathrm{m}$ to $275.7 \pm 108.3 \mu \mathrm{m}$. Goyal et al ${ }^{17}$ also stated that IVB has a short effect on visual acuity improvement and CMT reduction, which persists until the 12th week. After that, IVB can improve BCVA without affecting CMT reduction. Another study conducted by DRCR reported that IVB $1.25 \mathrm{mg}$ improved visual acuity (+9.7 letters) and reduced CMT $(-101 \mu \mathrm{m})$ and concluded that the treatment with IVB will improve the visual acuity by 1 month and sustain until 1 year with reinjection treatment. ${ }^{18}$

Another emerging treatment of DME is the use of intravitreal triamcinolone (IVTA). A randomized trial by Soheilian et al. ${ }^{15}$ compared three groups of treatment namely IVB, IVB with IVTA, and laser photocoagulation alone for 36 weeks. The study resulted IVB was superior to any other groups. Visual acuity improvement was significant until $36^{\text {th }}$ weeks while IVB with IVTA improved significantly only at $6^{\text {th }}$ and $12^{\text {th }}$ week and laser photocoagulation did not improve the visual acuity significantly. Even though the IVB/IVTA showed more superior results than the laser photocoagulation group, several side effects such as ocular hypertension, neovascular glaucoma, severe lens opacity were shown in the IVB/IVTA group. On the other hand, the reduction of CMT was statistically significant in all three groups only at 6 weeks. Improvement of the visual acuity did not correspond to the reduction of CMT. The study concluded that the increased of visual acuity was caused by an increased in macular perfusion after the intravitreal injection rather than reducing the vascular leakage or fluid absorption in the retinal interstitial.

Laser photocoagulation is the standard therapy for DME since the ETDRS study, however, several studies concluded treatment with intravitreal anti-VEGF alone showed more outstanding results. ${ }^{13,19}$ Pan-American collaborative retina study group evaluate the anatomical and functional outcome between IVB alone, grid laser photocoagulation $(G L P)$, and IVB plus GLP. The study revealed treatment with IVB alone is superior to any other groups. IVB resulted in higher improvement of visual acuity and higher reduction of CMT. ${ }^{13}$ The same result also reported in the BOLT study, a randomized prospective clinical trial with 80 patients, compared IVB $1.25 \mathrm{mg}$ with laser photocoagulation. Followup after 12 months resulted in higher increase in BCVA was found in group IVB (median 8 letters ETDRS, compared with a loss of 0.5 letters in the laser group). Whereas for CMT, the decrease was $129 \mu \mathrm{m}$ on average, compared to the laser group only $68 \mu \mathrm{m} .{ }^{19}$ However, in DRCR Protocol T study, a randomized clinical trial with 660 adults, compared the efficacy of aflibercept, bevacizumab, and ranibizumab reported $56 \%$ of patients needed laser photocoagulation at the 24th week because of the persistence of DME. ${ }^{18}$ Laser has shown to give synergistic effect when combined with intravitreal anti-VEGF. Combining laser with intravitreal injection can result in stable long-term results. ${ }^{20}$

According to Stewart, ${ }^{20}$ Bevacizumab has a half-life of 6.7 days and still survives in aqueous humour for 9.82 days. Bevacizumab will reach its maximum ability at that time before finally declining. IVB injection has a short half-life, so if re-injection is needed, the time between injections will be shorter, and the number of injections needed will be greater, therefore it increases the risk of complications of injections. Cheung et $\mathrm{al}^{21}$ reported endophthalmitis occurred after intravitreal injection in 0,057\% (9 of 15896 cases). In a 6-month evaluation study of IVB in DME, ocular complications were reported $<3.8 \%$ and systemic complications were reported $<4.6 \% .^{13}$ In this study, no ocular or systemic complications were reported. However, our limitation of the study is the short-term evaluation, therefore, another long-term study is needed to estimate the efficacy or safety of intravitreal bevacizumab. 


\section{CONCLUSION}

There are visual acuity improvement and central macular thickness reduction 3 months after IVB injection. These results strengthen IVB injection to be an alternative to adjuvant therapy in DME.

\section{REFERENCES}

1. Raymond NT, Varadhan L, Reynold DR, Bush K, Sankaranarayanan S, Bellary $S$, et al. Higher prevalence of retinopathy in diabetic patients of South Asian ethnicity compared with white Europeans in the community: a cross-sectional study. Diabetes Care. 2009 Mar;32(3):410-5. PubMed PMID: 19074992. PMCID: PMC2646018. Epub 2008/12/17.

2. Photocoagulation for diabetic macular edema. Early Treatment Diabetic Retinopathy Study report number 1. Early Treatment Diabetic Retinopathy Study research group. Arch Ophthalmol. 1985 Dec;103(12):1796-806. PubMed PMID: 2866759. Epub 1985/12/01.

3. Klein R, Klein BE, Moss SE, Cruickshanks KJ. The Wisconsin Epidemiologic Study of Diabetic Retinopathy. XV. The long-term incidence of macular edema. Ophthalmology. 1995 Jan;102(1):7-16. PubMed PMID: 7831044. Epub 1995/01/01. eng.

4. Bhagat N, Grigorian RA, Tutela A, Zarbin MA. Diabetic macular edema: pathogenesis and treatment. Survey of ophthalmology. 2009 Jan-Feb;54(1):1-32. PubMed PMID: 19171208. Epub 2009/01/28. eng.

5. Romero-Aroca P. Managing diabetic macular edema: The leading cause of diabetes blindness. World journal of diabetes. 2011 Jun 15;2(6):98-104. PubMed PMID: 21860693. PMCID: PMC3158878. Epub 2011/08/24. eng.

6. Chen E, Looman $M$, Laouri M, Gallagher M, Van Nuys $\mathrm{K}$, Lakdawalla D, et al. Burden of illness of diabetic macular edema: literature review. Current medical research and opinion. 2010 Jul;26(7):1587-97. PubMed PMID: 20429823. Epub 2010/05/01. eng.

7. Rahman K. Epidemiologi Retinopati Diabetika di Bagian Ilmu Penyakit Mata Fakultas Kedokteran UNAND/PERJAN RS DR. M Djamil Padang. Majalah Kedokteran Andalas. 2010.

8. Bringmann A, Reichenbach A, Wiedemann P. Pathomechanisms of cystoid macular edema. Ophthalmic research. 2004 Sep-Oct;36(5):241-9. PubMed PMID: 15583429. Epub 2004/12/08. eng.

9. Kim SH, Park JM. Comparison of Intravitreal Triamcinolone Versus Bevacizumab in Bilateral Diabetic Macular Edema by Optical Coherence Tomography (OCT) Patterns. J Korean Ophthalmol Soc. 2010 2/;51(2):210-9.
10. Intensive blood-glucose control with sulphonylureas or insulin compared with conventional treatment and risk of complications in patients with type 2 diabetes (UKPDS 33). UK Prospective Diabetes Study (UKPDS) Group. Lancet (London, England). 1998 Sep 12;352(9131):837-53. PubMed PMID: 9742976. Epub 1998/09/22. eng.

11. Meyer $\mathrm{CH}$. Current treatment approaches in diabetic macular edema. Ophthalmologica Journal international d'ophtalmologie International journal of ophthalmology Zeitschrift fur Augenheilkunde. 2007;221(2):118-31. PubMed PMID: 17380066. Epub 2007/03/24. eng.

12. Allingham MJ, Mukherjee $D$, Lally EB, Rabbani $H$, Mettu PS, Cousins SW, et al. A Quantitative Approach to Predict Differential Effects of Anti-VEGF Treatment on Diffuse and Focal Leakage in Patients with Diabetic Macular Edema: A Pilot Study. Translational Vision Science \& Technology. 2017;6(2):7-.

13. Arevalo JF, Fromow-Guerra J, Quiroz-Mercado $\mathrm{H}$, Sanchez JG, Wu L, Maia M, et al. Primary intravitreal bevacizumab (Avastin) for diabetic macular edema: results from the Pan-American Collaborative Retina Study Group at 6-month follow-up. Ophthalmology. 2007 Apr;114(4):743-50. PubMed PMID: 17398322. Epub 2007/04/03. eng.

14. Diabetic Retinopathy Clinical Research N, Scott IU, Edwards AR, Beck RW, Bressler NM, Chan CK, et al. A phase II randomized clinical trial of intravitreal bevacizumab for diabetic macular edema. Ophthalmology. 2007;114(10):1860-7. PubMed PMID: 17698196. Epub 2007/08/15.

15. Soheilian M, Ramezani A, Obudi A, Bijanzadeh B, Salehipour $M$, Yaseri $M$, et al. Randomized trial of intravitreal bevacizumab alone or combined with triamcinolone versus macular photocoagulation in diabetic macular edema. Ophthalmology. 2009 Jun;116(6):1142-50. PubMed PMID: 19376585. Epub 2009/04/21. eng.

16. Arevalo JF, Sanchez JG, Lasave AF, Wu L, Maia M, Bonafonte $S$, et al. Intravitreal Bevacizumab (Avastin) for Diabetic Retinopathy: The 2010 GLADAOF Lecture. Journal of ophthalmology. 2011;2011:584238-. PubMed PMID: 21584260. Epub 2011/03/30.

17. Regillo C, Holekamp N, Johnson M, Kaiser P. Retina and Vitreous: Basic and Clinical Science Course Section 12. 2011-2012. In: AAO [Internet]. San Fransisco.

18. Wells JA, Glassman AR, Ayala AR, Jampol LM, Aiello LP, Antoszyk AN, et al. Aflibercept, bevacizumab, or ranibizumab for diabetic macular edema. The New England journal of medicine. 2015 Mar 26;372(13):1193-203. PubMed PMID: 25692915. PMCID: PMC4422053. Epub 2015/02/19. eng. 
19. Rajendram R, Fraser-Bell S, Kaines A, Michaelides M, Hamilton RD, Esposti SD, et al. A 2-year prospective randomized controlled trial of intravitreal bevacizumab or laser therapy (BOLT) in the management of diabetic macular edema: 24-month data: report 3. Arch Ophthalmol. 2012 Aug;130(8):972-9. PubMed PMID: 22491395. Epub 2012/04/12. eng.

20. Stewart M. Phatophysiology of Diabetic Retinopathy. 2010. In: Diabetic Retinopathy [Internet]. Springer Science and Business Media.
21. Cheung CS, Wong AW, Lui A, Kertes PJ, Devenyi RG, Lam WC. Incidence of endophthalmitis and use of antibiotic prophylaxis after intravitreal injections. Ophthalmology. 2012 Aug;119(8):1609-14. PubMed PMID: 22480743. Epub 2012/04/07. eng.

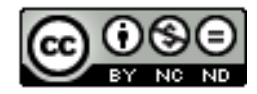

This work licensed under Creative Commons Attribution 